\title{
Passing the Baton to the Davis Editorial Office-January 2010
}

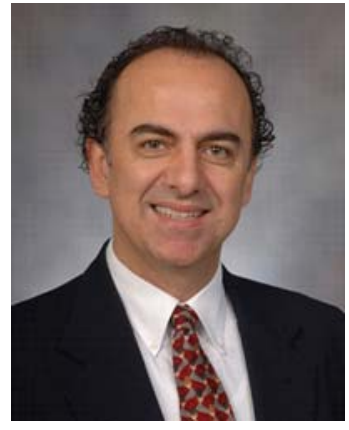

It is with excitement that I recently assumed the role of Editor-in-Chief for the Annals of Biomedical Engineering. It is with gratitude that I recognize the great work of the previous Editor-in-Chief, Prof. Larry McIntire, and the Editorial Office at Georgia Tech, as well as their efforts in elevating the ABME's acceptance, as evidenced by a steady increase in the journal's impact factor. Larry, a true leader in bioengineering, has always been an inspiration to many of us. Building on their success, the overriding goal of the Davis office is to elevate the stature of our Society's flagship journal to that of the premier journal in the field. Below, we offer a brief description of strengths, weaknesses, opportunities, and threats, in an effort to identify tangible objectives that can be implemented.

Strengths: Undoubtedly, the field of bioengineering or biomedical engineering is on the upswing, eliciting great interest and enjoying unprecedented growth. The Biomedical Engineering Society captures, to a large degree, the professional aspects of the field. The Annals of Biomedical Engineering, as the main journal of BMES, is in a position to continue capitalizing on the progress experienced in all aspects of the field.

Weaknesses: We need to make the journal more 'useful' to a larger number of BMES constituents and biomedical engineers in both academia and industry. The journal improved steadily and significantly under Larry McIntire's editorship and leadership, and it is our hope that it will reach the level of attracting the most significant papers from our community. The editorial process needs to be expedited such that scientific results find their way to publication in a more streamlined and significantly more expeditious manner.

Opportunities: As BMES continues to grow, it is poised to elevate its flagship journal to a major journal in bioengineering, allowing it to become the repository of the better or best work in the field. We also have an opportunity to expand our diversity by increasing the number of submissions from different scientific areas and from constituents around the world. We have already begun to diversify our Board of Associate Editors by inviting leading scholars from Europe, Asia, Australia, the Middle East, and Africa (please see the journal's masthead).

Threats: If ABME does not represent the wide spectrum of research and development in the field, then either some other journal(s) will do so, or, even worse, the field will be fragmented without an encompassing, comprehensive forum.

Plan of action: Though the journal's impact factor has been steadily increasing, collectively we should exert more effort to increase it significantly. We can accomplish this by (1) identifying, inviting, and accepting high quality work, and (2) publishing review articles that are of wide interest. We have established the position of Deputy Editor-in-Chief, and we are excited to report that the position will be filled by Scott I. Simon, a recognized leader in the field, who, among other duties, will solicit and oversee review articles. We envision that we will have at least two special issues every year. We have expanded the Board of Associate Editors by inviting scientific leaders from all over the world and from different bioengineering areas. Also of note is the fact that three of our Associate Editors are from industry. The objective is to prepare issues that researchers in both academe and industry will want to read and refer to on a consistent basis.

We have empowered Associate Editors to personally solicit submissions at scientific meetings and to also reach decisions based on their own evaluation of submissions. We need to continue striving to decrease turnaround time, increase diversity, and ensure that only high quality papers are published. For example, we have reduced the turnaround time for reviews from three weeks to two - a standard time in academic publishing. It is imperative that we accelerate publication if we are to elevate the Annals to a premier journal level.

To improve the editorial process, we are delighted to report that Dr. Holly Ober has joined the journal as its Managing Editor. Dr. Ober has her Ph.D. in Anthropology from the University of California, Davis. She brings her familiarity with the peer review process, her skills as a keen observer of the "big picture," and natural talent for details to the task of keeping the manuscripts moving efficiently through the system. We are privileged and lucky to have someone of her stature as the Managing Editor.

So, welcome to the inaugural issue of our journal under its new editorial office at Davis. As the new editors, our goal is to prepare every issue such that it is a compilation of outstanding papers spanning bioengineering and biomedical engineering, and covering basic issues as well as applications. Please embrace the Annals and please help us reach the scientific pinnacle that our flagship journal deserves.

\author{
K.A. Athanasiou \\ Davis, CA \\ Electronic mail: athanasiou@ucdavis.edu
}

